\title{
Correction to: Design of Knowledge Base Model for Home Loan: Case Study of a Bank in India
}

\author{
Subhasis Sen and K. Rajagopal
}

\section{Correction to:}

Chapter 21 in: S. Sikdar et al. (eds.), Role of IT- ITES in Economic Development of Asia, https://doi.org/10.1007/978-981-15-4206-0_21

In the original version of the book, the following correction has been incorporated: The affiliation of Dr. Subhasis Sen has been changed from "SCMHRD, Balaji Institute of Telecom and Management (BITM), Sri Balaji University, Pune, India" to "Balaji Institute of Telecom and Management (BITM), Sri Balaji University, Pune, India". The correction chapter and the book have been updated with the change. 